\title{
Clinical characteristics and perinatal outcomes of women with COVID-19 in Wuhan: retrospective case series
}

\author{
Hao Zeng ${ }^{1}$, Yujie Liu ${ }^{1}$, Lan Dong ${ }^{1}$, Qifan Zhang ${ }^{1}$, Shengmin Zhao ${ }^{1}$, Luowen Xin ${ }^{1}$, Panwen \\ Tian $^{1}$, and Zhixin Huang ${ }^{1}$ \\ ${ }^{1}$ Affiliation not available
}

July 20, 2020

\begin{abstract}
Background This study was undertaken to evaluate the clinical characteristics and perinatal outcomes of pregnant women with COVID-19 in different trimesters and to determine the possibility of vertical transmission of the disease. Methods Medical records of 25 consecutive pregnant women with laboratory-confirmed COVID-19 who were admitted to Renmin Hospital of Wuhan University, Wuhan, China, from Feb 1 to Mar 20, 2020 were reviewed. Results Eleven cases were in early and middle pregnancy, and 14 cases were in late pregnancy. Seven of 25 women $(28.0 \%)$ had mild disease, $15(60.0 \%)$ had moderate disease, and $3(12.0 \%)$ had severe disease. The most common symptoms of patients were fever (48.0\%) and cough (48.0\%), though $7(28.0 \%)$ of them were asymptomatic at admission. Fever was more prevalent in early and middle pregnancy than in late pregnancy $(72.7 \%$ vs. $28.6 \%, \mathrm{P}=0.028)$. Among patients in early and middle pregnancy, there were 1 spontaneous abortion and 3 induced abortions, but no intrauterine growth restriction was observed among ongoing pregnancies. All 14 patients in late pregnancy underwent a cesarean section, with 4 premature deliveries (28.6\%). No neonatal asphyxia or death was recorded. Nasopharyngeal swab samples from 6 neonates were tested for SARZ-CoV-2, and all were negative. In one neonate, the anal swab was positive for SARS-CoV-2, and IgG and IgM were increased. Conclusions The clinical characteristics of COVID-19 in early and middle pregnant women were similar to those in late pregnancy. There is a potential risk of vertical transmission in SARS-CoV-2.
\end{abstract}

Article type: Original Article

Clinical characteristics and perinatal outcomes of women with COVID-19 in Wuhan: retrospective case series

\section{Running title}

Characteristics of pregnant women with COVID-19

Hao Zeng ${ }^{1}$, Yujie Liu ${ }^{1}$, Lan Dong ${ }^{2}$, Qifan Zhang ${ }^{2}$, Shengmin Zhao ${ }^{3}$, Luowen Xin ${ }^{3}$, Panwen Tian ${ }^{3}$, Zhixin Huang $^{2}$

Hao Zeng, Yujie Liu and Lan Dong contributed equally to this article.

${ }^{1}$ Department of Respiratory and Critical Care Medicine, West China Hospital, West China School of Medicine, Sichuan University, Chengdu, China

${ }^{2}$ Department of Obstetrics and Gynecology, Renmin Hospital of Wuhan University, Wuhan, China

${ }^{3}$ Department of Respiratory and Critical Care Medicine, Lung Cancer Treatment Center, West China Hospital, Sichuan University, Chengdu, China 
* Address correspondence to Panwen Tian(mrascend@163.com), Department of Respiratory and Critical Care Medicine, Lung Cancer Treatment Center, West China Hospital, Sichuan University, No. 37 GuoXue Alley, Chengdu, 610041, Sichuan Province, China and Zhixin Huang(huangzx31@sina.com), Department of Obstetrics and Gynecology, Renmin Hospital of Wuhan University, No.238 Jiefang Road, Wuhan, 436000, Hubei Province, China.

PHONE: +86 28 85423998,

FAX: +862885582944

\section{Acknowledgments}

We thank all the patients included in this study.

\section{ABSTRACT}

\section{Background}

This study was undertaken to evaluate the clinical characteristics and perinatal outcomes of pregnant women with COVID-19 in different trimesters and to determine the possibility of vertical transmission of the disease.

\section{Methods}

Medical records of 25 consecutive pregnant women with laboratory-confirmed COVID-19 who were admitted to Renmin Hospital of Wuhan University, Wuhan, China, from Feb 1 to Mar 20, 2020 were reviewed.

\section{Results}

Eleven cases were in early and middle pregnancy, and 14 cases were in late pregnancy. Seven of 25 women $(28.0 \%)$ had mild disease, $15(60.0 \%)$ had moderate disease, and $3(12.0 \%)$ had severe disease. The most common symptoms of patients were fever (48.0\%) and cough (48.0\%), though 7 (28.0\%) of them were asymptomatic at admission. Fever was more prevalent in early and middle pregnancy than in late pregnancy $(72.7 \%$ vs. $28.6 \%, \mathrm{P}=0.028)$. Among patients in early and middle pregnancy, there were 1 spontaneous abortion and 3 induced abortions, but no intrauterine growth restriction was observed among ongoing pregnancies. All 14 patients in late pregnancy underwent a cesarean section, with 4 premature deliveries (28.6\%). No neonatal asphyxia or death was recorded. Nasopharyngeal swab samples from 6 neonates were tested for SARZ-CoV-2, and all were negative. In one neonate, the anal swab was positive for SARS-CoV-2, and IgG and IgM were increased.

\section{Conclusions}

The clinical characteristics of COVID-19 in early and middle pregnant women were similar to those in late pregnancy. There is a potential risk of vertical transmission in SARS-CoV-2.

\section{Keywords}

Coronavirus disease 2019 (COVID-19); Severe acute respiratory syndrome coronavirus 2 (SARS-CoV-2); pregnant; characteristics

\section{Introduction}

Severe acute respiratory syndrome coronavirus 2 (SARS-CoV-2), first reported in Wuhan, Hubei province, China at the end of 2019, spread rapidly throughout China in a few weeks and has become a global health problem $^{1,2}$. The World Health Organization (WHO) proclaimed the outbreak a Public Health Emergency of International Concern (PHEIC) on January 30, 2020 and named the disease as the Coronavirus Disease 2019 (COVID-19) on February 12, 20201,3 . Knowledge of the epidemiological characteristics, pathogenesis, symptoms, diagnosis, prevention and treatment of this emerging agent have increased rapidly ${ }^{4-9}$.

However, data on pregnant women with COVID-19 were limited and myalgia, and no severe case of COVID19 or SARS-CoV-2 associated death was reported, especially in early and middle pregnancy. A retrospective 
review conducted by $\mathrm{Chen}^{10}$ et al showed that the most common symptoms of COVID-19 in pregnant women were fever, cough and myalgia and no severe COVID-19 or died development. But all the pregnant women in the research were in their third trimester of pregnancy. The maternal immune system is extremely sensitive and easily challenged by external stimulation in early pregnancy, with effects on fetal growth and development ${ }^{11,12}$. Greater emphasis must be placed on the description of pregnant women infected with SARS-CoV-2 in early and middle pregnancy.

The body of literature on clinical characteristics and perinatal outcomes of women with COVID-19 during the first or second trimesters is limited. In addition, whether SARS-CoV-2 can be transmitted vertically in utero is controversial. We retrospectively analyzed the medical records of 25 consecutive pregnant women in different stages, and investigated the clinical characteristics, fetal status and pregnancy outcome.

\section{Methods}

\section{Patients}

This retrospective study included pregnant women from East District of People's Hospital of Wuhan University (Wuhan, China). All pregnant women who were diagnosed with COVID-19 according to WHO interim guidance between Feb 1, 2020 and Mar 20, 2020 were screened in our study. We classified the women into two groups, namely early and middle pregnancy (1-27 weeks of gestation) and late pregnancy ([?]28 weeks of gestation). Ethics approval was granted by the ethics board of the Institute of People's Hospital of Wuhan University (WDRY2020-K068). Informed consent was waived in view of the retrospective nature of the study.

\section{Procedures}

Perinatal data including clinical symptoms (collected at admission), laboratory findings (blood specimens were collected at admission), chest CT images (with good protection of lead clothing), treatment (including drugs, intensive care and mechanical ventilation), maternal complications and pregnancy outcomes were collected from electronic medical records. The neonates' information including gestational age, birth weight, Apgar score, laboratory findings and adverse events were analyzed. Data were independently checked for accuracy by two investigators (P. Tian and Z. Huang). Clearance of viral RNA was defined as two consecutive negative nucleic acid tests on respiratory tract specimens, taken at least 24 hours apart. Classification for mild, moderate, severe and critical COVID-19 was based on the Chinese guideline for COVID-19 management (version 5.0) ${ }^{13}$.

\section{Qualitative RT-PCR and SARS-CoV-2 antibody testing}

All maternal cases had SARS-CoV-2 infection confirmed by real-time reverse transcriptase polymerase chain reaction (RT-PCR) using the Chinese Center for Disease Control and Prevention (CDC) recommended assay (BioGerm, Shanghai, China) as described previously. ${ }^{10}$ Conditions for amplification included reverse transcription at $50^{\circ} \mathrm{C}$ for $15 \mathrm{~min}$, pre-denaturation at $95^{\circ} \mathrm{C}$ for $15 \mathrm{~min}$, and 45 cycles of $94^{\circ} \mathrm{C}$ for 15 seconds and $60^{\circ} \mathrm{C}$ for 30 seconds. A cycle threshold value (Ct-value) less than 40 was defined as positive. Neonatal nasopharyngeal and anal swab samples were collected in a subset of neonates at birth, and sent to the laboratory of the Wuhan Center for Disease Control and Prevention for detection of SARS-CoV-2 RNA by RT-PCR, as described above. IgG and IgM were analysed in blood specimens, using a novel chemiluminescent immunoassay (CLIA assays Kit, YHLO) based strictly on the manufacturer's instructions. Cut-off thresholds for SARS-CoV-2 IgM and IgG were both $10.0 \mathrm{AU} / \mathrm{mL}$. Sample collection, processing, and laboratory testing were based on WHO guidance ${ }^{14}$.

\section{Statistical analysis}

Demographic and clinical characteristics of patients with COVID-19 were analyzed using descriptive statistics. The Mann-Whitney U test and Student t-test were used to determine significant differences between continuous variables, as appropriate. The adjusted Chi-square test was used to determine significant differences between categorical variables. Statistical significance was set at two-sided P-values [?] 0.05. All 
analyses were performed with Statistical Product and Service Solutions (SPSS) version 21 (IBM Corp, Armonk, NY).

\section{Results}

\section{Clinical characteristic and laboratory abnormalities}

Twenty-five consecutive pregnant women with COVID-19 confirmed by RT-PCR for SARS-CoV-2 are included in this analysis. Eleven cases $(44.0 \%)$ were in the early and middle pregnancy group, and the remainder were in the late pregnancy group (Table 1). Seven $(28.0 \%)$ had mild disease, $15(60.0 \%)$ had moderate disease, and $3(12.0 \%)$ had severe disease. The most common symptoms were fever $(12 / 25,48.0 \%)$ and cough $(12 / 25,48.0 \%)$, followed by sputum production (16.0\%), dyspnea (8.0\%), fatigue (4.0\%), anorexia $(4.0 \%)$, sore throat $(4.0 \%)$, myalgia $(4.0 \%)$ and diarrhea (4.0\%). Seven (28.0\%) were asymptomatic. Fever was more prevalent in early and middle pregnancy than in late pregnancy $(72.7 \%$ vs. $28.6 \%, \mathrm{p}=0.028)$, but not statistically in other symptoms of two groups (Table 1 ).

Data from laboratory tests showed that creatinine and D-Dimer was significantly lower in early and middle pregnancy than that in late pregnancy $(40.0 \mathrm{umol} / \mathrm{L}$ vs. $48.0 \mathrm{umol} / \mathrm{L}, \mathrm{P}=0.033 ; 0.8 \mathrm{mg} / \mathrm{L}$ vs. $1.7 \mathrm{mg} / \mathrm{L}$, $\mathrm{P}=0.038$, respectively). Other laboratory findings, including leukocyte count, hemoglobin, albumin, globulin and alanine transaminase were similar between the two groups (Table 2).

All of the patients had chest X-ray or CT scan imaging on admission, the majority (60.0\%) had bilateral abnormalities including ground-glass opacity or patchy shadowing, and the remainder had unilateral abnormalities. Radiographic presentations were similar in the early and middle pregnancy and late pregnancy groups (Table 2).

\section{RNA clearance time and length of stay in two groups}

Mean viral clearance time was longer (29.0 days) in the early and middle pregnancy group compared to the late pregnancy group (18.4 days); $\mathrm{P}=0.038$. Because patients had to stay hospitalized until negative PCR. So, length of hospital stay was greater in the early and middle pregnancy group (28.0 days) compared to the late pregnancy group (11.5 days); $\mathrm{P}=0.037$ (Table 1 ).

\section{Treatment, Maternal outcomes and Effect on the fetus in early and middle pregnancy}

In the 11 patients that were in early and middle pregnancy at COVID-19 diagnosis, gestational age ranged from 4 weeks to 26 weeks. Two (18.2\%) presented with severe disease, $6(54.5 \%)$ had moderate disease, and $3(27.3 \%)$ were clinically mild. All 11 received antiviral treatment (Arbidol/Ribavirin/Lianhua Qingwen/Oseltamivir), $7(63.6 \%)$ received antibiotic therapy, and $3(27.3 \%)$ were treated with systemic glucocorticoids. None required mechanical ventilation, and all were cured.

One patient developed depression, and one (patient 11) experienced spontaneous abortion 16 days after she was diagnosed with COVID 19. Notably, 3 patients $(6,7$ and 10) requested termination of their pregnancies owing to concerns about COVID-19, after they had recovered. Fetal growth was assessed by serial ultrasound scans every 2 weeks among the 7 women with ongoing pregnancies. No intrauterine growth retardation (IUGR) was observed during the study period (Table 3). Fetal surveillance with antenatal cardiotocography and umbilical arterial Doppler velocimetry was satisfactory.

\section{Treatment, Maternal complications and Pregnancy outcomes in late pregnancy}

Among 14 patients in late pregnancy, gestational age at diagnosis ranged from 28 weeks to 39 weeks. Only one $(7.1 \%)$ developed severe disease and the others were moderate $(57.1 \%)$ or mild type $(35.7 \%)$. Hypothyroidism was observed in patient 1, gestational diabetes mellitus (GDM) was observed in patient 7 without use of corticosteroid and pregnancy-induced hypertension (PIH) was showed in patient 14. All patients received oxygen inhalation and antiviral treatment(Arbidol/Ribavirin/Lianhua Qingwen/Oseltamivir). Systemic glucocorticoids were used in $72.7 \%$ of patients and antibiotics were used in $57.1 \%$ of patients. All 
had been discharged for recovered from the disease as of April 10. No patients developed critical disease, requiring mechanical ventilation, or died of COVID-19.

All patients had a caesarean section in their third trimester. Four of them had preterm labor between 33 weeks and 37 weeks. Three neonates $(21.4 \%)$ had a low birthweight $(<2500 \mathrm{~g})$. All the fourteen neonates had a 1-min Apgar score of 9 and a 5-min Apgar score of 10 except one. Neonate 12 had a 1-min and 5-min Apgar score of 7 and 9, respectively.

Nasopharyngeal swab specimens were collected successfully in 6 cases at birth (neonate 1, 3, 4, 7, 11 and 12) for SARS-CoV-2 test by RT-PCR, and all the results were negative. Additional SARS-CoV-2 test was performed on cord blood of neonate 7 and the result was negative. However, the anal swab which performed just after delivery from neonate 11 was positive for SARS-CoV-2. Additionally, IgG and IgM antibody against SARS-CoV-2 were analyzed from the peripheral blood of neonate 11. Both were increased with the IgG titer of 140.32 (reference, $0-10 \mathrm{AU} / \mathrm{ml}$ ) and IgM titer of 45.83 (reference, 0-10 AU/ml), respectively (Table 4).

\section{Discussion}

We reported clinical features and perinatal outcomes from 25 pregnant women with COVID-19 including 11 in the first and second trimester and 14 in the third trimester. The common clinical characteristics were similar between the two groups. None of the patients developed critical ill pneumonia, requiring mechanical ventilation, or died of COVID-19. Notably, based on our findings, there may be a potential risk of vertical transmission in SARS-CoV-2.

According to our study, the most common onset clinical manifestations of COVID-19 in the first and second trimester group showed the typical symptoms, such as fever and cough, similar to those in the late stage of pregnancy group and reported by Liu and colleagues ${ }^{15}$, while were different from those with SARS who mainly showed fever, myalgia, chills and rigors et $\mathrm{al}^{11}$. But notably, a considerable proportion of patients are asymptomatic in both groups, similar to those of $28 \%$ (10/36) in children with COVID-19, which called "covert transmitter" and may propagate the virus transmit silently and make it more difficult to control infection ${ }^{16,17}$. Similarly, Meng and colleagues showed abnormal CT images and clinical course of asymptomatic cases with COVID-19 at admission and highlight the vital role of CT for early detection of the highly suspicious, asymptomatic cases ${ }^{18}$. Although laboratory tests indicated that creatinine and D-Dimer were significantly higher in the third trimester group compared with the first and second trimester group, none of the patients developed critical disease or died of COVID-19. This can be well understood by complex physiological changes during pregnancy, for example, D-dimers can be increased to $50 \%$ above baseline during the third trimester ${ }^{19}$. The predominant pattern of abnormal chest CT findings observed was bilateral in both groups, which was similar to those observed in the non-pregnant patients ${ }^{20}$.

There is a theoretical risk of worse perinatal outcomes for infected pregnant women because of the unstable immune system and physiological adaptive changes, especially in the early stage of pregnancy. As showed in our study, the RNA clearance time of patients in the first and second trimester group was significantly longer than that in late pregnancy group. Additionally, take severe acute respiratory syndrome (SARS) as an example, fatality rate of $25 \%$, Intensive Care Unit (ICU) admissions (50\%) and mechanical ventilation (33\%) were reported by Wong and colleagues in pregnant women compared with nonpregnant adult population ${ }^{11}$. Higher maternal mortality rate of $50 \%$ were reported during the epidemic Asian flu of $1957^{21}$. However, our study reveals a case fatality rate of $0 \%$ in pregnant women with COVID-19 which is in line with those reported by Chen and colleagues ${ }^{10}$. Additionally, severe maternal complications were not observed in all women by our study. Our data do not show an increased risk of severe disease among pregnant women. The perinatal outcomes of pregnant women are more promising compared with SARS. Activation of different Thelper (Th) lymphocytes result in the different disease severity. Patients with SARS activated Th1 immunity preferentially which is proinflammatory chiefly, leading to elevation of proinflammatory cytokines, such as IL-6, a risk factor of mortality in COVID-19 patients. However, patients with COVID-19 showed activation Th2 immunity at the same time, promoting the expression of anti-inflammatory cytokines such as IL-4 and 
IL-102, 22, 23. The Th1-Th2 shift may contribute the lesser severity of perinatal outcomes of patients with COVID-19 compared to those with SARS.

In our study, no IUGR was observed and fetal surveillance was satisfactory during the study period. Wong and colleagues reported the spontaneous miscarriage of $57 \%(4 / 7)$ in pregnant women with SARS ${ }^{11}$. The higher rate of spontaneous miscarriage during the 1st trimester was probably attribute to hypoxia or maternal respiratory failure caused by SARS-related acute respiratory distress. Additionally, impact of severe maternal debilitating illness, such as renal failure, disseminated intravascular coagulopathy and cardiovascular collapse, maybe was another one reason ${ }^{11,24}$.

There is an extremely possibility risk of vertical transmission based on our findings. Previously, no intrauterine fetal infections were reported by Chen et al ${ }^{10}$ in all nine pregnant women with COVID-19 who underwent a caesarean section during the late pregnancy, the results was similar to those showed by Zhang et $\mathrm{al}^{25}$ in a retrospective study which including 10 infants who were conceived by patients with COVID-19, all infants were negative using RT-PCR analysis of throat swabs. Little existing evidences for vertical transmission were based on positive results of IgM antibody in neonatal serum ${ }^{26,27}$. So, more definitive evidence is needed to ascertain the possibility of intrauterine vertical transmission during pregnancy ${ }^{28}$. Cases in which both antibody and nucleic acid tests are positive have not been reported. According to our study, although the result of nasopharyngeal swab was negative, vertical transmission of SARS-CoV-2 from mother to her neonate was confirmed by the coincident positive results of anal swab and serum sample for IgG and IgM antibody against SARS-CoV-2 at one neonate. A possible reason for why nasopharyngeal swab was negative is that SARS-CoV-2 transmitted through oral-fecal route ${ }^{29}$. Because the days from onset to delivery were as long as 31days in our case, the infection had possibly shifted from oral to anal. As those reported by Zhang and colleague, the positive rate of anal swab was higher than that of oral swab in the later stage of infection ${ }^{30}$. So, the neonate may has already infected in the early stage, however, cord blood, amniotic fluid or breast milk test is needed to ascertain this deduction in the future.

There are a few limitations in our study. First, recall bias and selection bias are inevitable because of our retrospective method. Second, relatively small sample size of pregnant women with COVID-19 remind us interpret the findings cautiously. However, we believe our conclusions are valid because more results are in line with existing studies about pregnant women with COVID-19.

In conclusion, the clinical characteristics of women with COVID-19 in early and middle pregnant women were similar to those in late pregnancy, although RNA clearance time and length of stay were significantly different between the two groups. In addition, our results showed the important role of anal swab for SARS-CoV-2 in neonates for diagnosis of fecal-oral infection and the potential risk of vertical transmission in SARS-CoV-2.

\section{Declaration of interests}

We declare no competing interests.

\section{Funding}

This work was supported by the National Key Development Plan for Precision Medicine Research of China (2017YFC0910004), the National Major Sci-Tech Project of China (2017ZX10103004-012), the Major Science and Technology Innovation Project of Chengdu City (2020-YF08-00080-GX), and the National Science Foundation of China (81871890, 91859203).

\section{References}

1.Zhang JJ, Dong X, Cao YY, et al. Clinical characteristics of 140 patients infected with SARS-CoV-2 in Wuhan, China. Allergy. 2020.

2.Huang C, Wang Y, Li X, et al. Clinical features of patients infected with 2019 novel coronavirus in Wuhan, China. The Lancet. 2020,395(10223):497-506. 
3.She J, Jiang J, Ye L, et al. 2019 novel coronavirus of pneumonia in Wuhan, China: emerging attack and management strategies. Clin Transl Med. 2020,9(1):19.

4.Xu XW, Wu XX, Jiang XG, et al. Clinical findings in a group of patients infected with the 2019 novel coronavirus (SARS-Cov-2) outside of Wuhan, China: retrospective case series. BMJ. 2020,368:m606.

5.Li Q, Guan X, Wu P, et al. Early Transmission Dynamics in Wuhan, China, of Novel Coronavirus-Infected Pneumonia. N Engl J Med. 2020.

6.Chen N, Zhou M, Dong X, et al. Epidemiological and clinical characteristics of 99 cases of 2019 novel coronavirus pneumonia in Wuhan, China: a descriptive study. The Lancet. 2020,395(10223):507-13.

7.Lu R, Zhao X, Li J, et al. Genomic characterisation and epidemiology of 2019 novel coronavirus: implications for virus origins and receptor binding. The Lancet. 2020.

8.Sun P, Lu X, Xu C, et al. Understanding of COVID-19 based on current evidence. J Med Virol. 2020.

9.Lu H, Stratton CW, Tang YW. Outbreak of pneumonia of unknown etiology in Wuhan, China: The mystery and the miracle. J Med Virol. 2020,92(4):401-2.

10.Chen H, Guo J, Wang C, et al. Clinical characteristics and intrauterine vertical transmission potential of COVID-19 infection in nine pregnant women: a retrospective review of medical records. The Lancet. 2020,395(10226):809-15.

11.Wong SF, Chow KM, Leung TN, et al. Pregnancy and perinatal outcomes of women with severe acute respiratory syndrome. Am J Obstet Gynecol. 2004,191(1):292-7.

12.Bouthry E, Picone O, Hamdi G, et al. Rubella and pregnancy: diagnosis, management and outcomes. Prenat Diagn. 2014,34(13):1246-53.

13. National Health and Health Commission of the People's Republic of China. Diagnosis and treatment guidelines for 2019 novel coronavirus pneumonia (draft version 5). Feb 4, 2020.http://www.nhc.gov.cn/yzygj/s7653p/202002/3b09b894ac9b4204a79db5b8912d4440.shtml (accessed March 12, 2020; in Chinese).

14. Wahla AS, Uzbeck M, El Sameed YA, et al. WHO. Laboratory testing for 2019 novel coronavirus (2019$\mathrm{nCoV}$ ) in suspected human cases. Interim guidance. Jan 17, 2020. https://www.who.int/publicationsdetail/laboratory-testing-for-2019novel-coronavirus-in-suspected-human-cases-20200117 (accessed Feb 4, 2020).

15.Liu D, Li L, Wu X, et al. Pregnancy and Perinatal Outcomes of Women With Coronavirus Disease (COVID-19) Pneumonia: A Preliminary Analysis. AJR Am J Roentgenol. 2020:1-6.

16.Ye F, Xu S, Rong Z, et al. Delivery of infection from asymptomatic carriers of COVID-19 in a familial cluster. International Journal of Infectious Diseases. 2020.

17.Qiu H, Wu J, Hong L, et al. Clinical and epidemiological features of 36 children with coronavirus disease 2019 (COVID-19) in Zhejiang, China: an observational cohort study. The Lancet Infectious Diseases. 2020.

18.Meng H, Xiong R, He R, et al. CT imaging and clinical course of asymptomatic cases with COVID-19 pneumonia at admission in Wuhan, China. J Infect. 2020,81(1):e33-e9.

19.Abbassi-Ghanavati M GL, Cunningham FG. Pregnancy and laboratory studies: a reference table for clinicians. Obstet Gynecol. 2009,114:1326-31.

20.Shi H, Han X, Jiang N, et al. Radiological findings from 81 patients with COVID-19 pneumonia in Wuhan, China: a descriptive study. The Lancet Infectious Diseases. 2020.

21.Greenberg M, Jacobziner H, Pakter J, et al. Maternal mortality in the epidemic of Asian influenza, New York City, 1957. American Journal of Obstetrics and Gynecology. 1958,76(4):897-902. 
22.Wong CK, Lam CW, Wu AK, et al. Plasma inflammatory cytokines and chemokines in severe acute respiratory syndrome. Clin Exp Immunol. 2004,136(1):95-103.

23.Ruan Q, Yang K, Wang W, et al. Correction to: Clinical predictors of mortality due to COVID-19 based on an analysis of data of 150 patients from Wuhan, China. Intensive Care Med. 2020.

24.Schwartz DA, Graham AL. Potential Maternal and Infant Outcomes from (Wuhan) Coronavirus 2019nCoV Infecting Pregnant Women: Lessons from SARS, MERS, and Other Human Coronavirus Infections. Viruses. 2020,12(2).

25.Zhang L, Jiang Y, Wei M, et al. [Analysis of the pregnancy outcomes in pregnant women with COVID-19 in Hubei Province]. Zhonghua Fu Chan Ke Za Zhi. 2020,55(0):E009.

26.Dong L, Tian J, He S, et al. Possible Vertical Transmission of SARS-CoV-2 From an Infected Mother to Her Newborn. Jama. 2020.

27.Zeng H, Xu C, Fan J, et al. Antibodies in Infants Born to Mothers With COVID-19 Pneumonia. Jama. 2020 .

28.Kimberlin DW, Stagno S. Can SARS-CoV-2 Infection Be Acquired In Utero?: More Definitive Evidence Is Needed. Jama. 2020.

29.Wang W, Xu Y, Gao R, et al. Detection of SARS-CoV-2 in Different Types of Clinical Specimens. Jama. 2020 .

30.Zhang W, Du RH, Li B, et al. Molecular and serological investigation of 2019-nCoV infected patients: implication of multiple shedding routes. Emerg Microbes Infect. 2020,9(1):386-9.

Table 1. Characteristics of 25 pregnant women with COVID-19

\begin{tabular}{|c|c|c|c|c|}
\hline & Total $(n=25)$ & $\begin{array}{l}\text { the first and } \\
\text { second trimester } \\
(n=11)\end{array}$ & $\begin{array}{l}\text { the third } \\
\text { trimester }(\mathrm{n}=14)\end{array}$ & $P$-value \\
\hline Age, mean $\pm S D$ & $30.1 \pm 4.0$ & $30.3 \pm 4.7$ & $30.0 \pm 3.5$ & 0.869 \\
\hline $\begin{array}{l}\text { Health care } \\
\text { worker, n (\%) } \\
\text { Signs and } \\
\text { symptoms, n } \\
(\%)\end{array}$ & $6(24 \%)$ & $3(27.3 \%)$ & $3(21.4 \%)$ & 1.000 \\
\hline Fever & $12(48.0 \%)$ & $8(72.7 \%)$ & $4(28.6 \%)$ & 0.028 \\
\hline Cough & $12(48.0 \%)$ & $6(54.5 \%)$ & $6(42.9 \%)$ & 0.561 \\
\hline Expectoration & $4(16.0 \%)$ & $2(18.2 \%)$ & $2(14.3 \%)$ & 1.000 \\
\hline Dyspnea & $2(8.0 \%)$ & $0(0)$ & $2(14.3 \%)$ & 0.487 \\
\hline Fatigue & $1(4.0 \%)$ & $1(9.1 \%)$ & $0(0)$ & 0.440 \\
\hline Poor appetite & $1(4.0 \%)$ & $0(0)$ & $1(7.1 \%)$ & 1.000 \\
\hline Sore throat & $1(4.0 \%)$ & $0(0)$ & $1(7.1 \%)$ & 1.000 \\
\hline Muscle ache & $1(4.0 \%)$ & $1(9.1 \%)$ & $0(0)$ & 0.440 \\
\hline Diarrhea & $1(4.0 \%)$ & $0(0)$ & $1(7.1 \%)$ & 1.000 \\
\hline Asymptomatic & $7(28.0 \%)$ & $3(27.3 \%)$ & $4(28.6 \%)$ & 1.000 \\
\hline $\begin{array}{l}\text { Onset of } \\
\text { symptom to } \\
\text { admission, d, } \\
\text { mean } \pm \text { SD }\end{array}$ & $7.5 \pm 4.5$ & $8.9 \pm 4.3$ & $6.4 \pm 4.5$ & 0.166 \\
\hline $\begin{array}{l}\text { Antibiotic } \\
\text { therapy, n (\%) }\end{array}$ & $15(60.0 \%)$ & $7(63.6 \%)$ & $8(57.1 \%)$ & 1.000 \\
\hline
\end{tabular}



Use of
$11(44.0 \%)$
$3(27.3 \%)$
$8(72.7 \%)$
0.277
corticosteroid,
n (\%)
RNA clearance
$23.7 \pm 11.7$
$29.0 \pm 11.5$
$18.4 \pm 9.7$
0.038
time, d,
mean \pm SD
Length of Stay,
$13.0(9.0,28.0)$
$28.0(13.0,35.0)$
$11.5(8.8,21.0)$
0.037
d, median (Q1,
Q3)

Abbreviations: SD, standard deviation

Table 2. Laboratory and CT findings of 25 pregnant women with COVID-19

\begin{tabular}{|c|c|c|c|c|}
\hline & Total $(n=25)$ & $\begin{array}{l}\text { the first and } \\
\text { second trimester } \\
(n=11)\end{array}$ & $\begin{array}{l}\text { the third } \\
\text { trimester }(\mathrm{n}=14)\end{array}$ & $P$-value \\
\hline \multicolumn{5}{|l|}{$\begin{array}{l}\text { Laboratory } \\
\text { characteristics }\end{array}$} \\
\hline $\begin{array}{l}\text { White blood } \\
\text { cell count } \\
\left(\times 10^{9} / \mathrm{L}\right) \text {, } \\
\text { median (Q1, } \\
\text { Q3) }\end{array}$ & $6.9(5.4,8.7)$ & $5.6(4.6,8.9)$ & $7.5(6.1,9.1)$ & 0.171 \\
\hline $\begin{array}{l}\text { Neutrophil } \\
\text { count } \\
\left(\times 10^{9} / \mathrm{L}\right) \text {, } \\
\text { median (Q1, } \\
\text { Q3) }\end{array}$ & $5.1(3.6,7.5)$ & $4.1(3.1,7.5)$ & $5.5(4.3,7.7)$ & 0.139 \\
\hline $\begin{array}{l}\text { Lymphocyte } \\
\text { count } \\
\left(\times 10^{9} / \mathrm{L}\right) \\
\text { mean } \pm \text { SD }\end{array}$ & $1.3 \pm 0.4$ & $1.4 \pm 0.4$ & $1.3 \pm 0.4$ & 0.488 \\
\hline $\begin{array}{l}\text { Platelet count, } \\
\left(\times 10^{9} / \mathrm{L}\right) \\
\text { mean } \pm \text { SD }\end{array}$ & $212.3 \pm 59.6$ & $221.9 \pm 59.8$ & $204.7 \pm 60.5$ & 0.486 \\
\hline $\begin{array}{l}\text { Hemoglobin, } \\
\text { (g/L) median } \\
\text { (Q1, Q3) }\end{array}$ & $\begin{array}{l}115.0(109.0 \\
124.5)\end{array}$ & $\begin{array}{l}115.0 \\
124.0)\end{array}$ & $\begin{array}{l}115.5(105.0 \\
126.3)\end{array}$ & 0.767 \\
\hline $\begin{array}{l}\text { CD3 }(/ \mathrm{uL}), \\
\text { median }(\mathrm{Q} 1, \\
\text { Q3) }\end{array}$ & $\begin{array}{l}895.0(728.0 \\
1161.0)\end{array}$ & $\begin{array}{l}1095.0 \\
(905.0,1360.0)\end{array}$ & $\begin{array}{l}767.0(718.5 \\
965.5)\end{array}$ & 0.157 \\
\hline $\begin{array}{l}\mathrm{CD} 4(/ \mathrm{uL}), \\
\operatorname{mean} \pm \mathrm{SD}\end{array}$ & $502.5 \pm 210.9$ & $612.3 \pm 194.0$ & $429.2 \pm 198.0$ & 0.100 \\
\hline $\begin{array}{l}\text { CD8 }(/ \mathrm{uL}) \text {, } \\
\text { median (Q1, } \\
\text { Q3) }\end{array}$ & $\begin{array}{l}424.0(342.0 \\
487.0)\end{array}$ & $\begin{array}{l}426.5(325.8 \\
548.0)\end{array}$ & $\begin{array}{l}424.0(279.0 \\
452.5)\end{array}$ & 0.556 \\
\hline $\begin{array}{l}\text { Albumin }(\mathrm{g} / \mathrm{L}) \text {, } \\
\text { median }(\mathrm{Q} 1, \\
\text { Q3) }\end{array}$ & $37.2(33.1,41.8)$ & $38.3(35.4,43.5)$ & $36.8(32.7,38.6)$ & 0.347 \\
\hline
\end{tabular}




\begin{tabular}{|c|c|c|c|c|}
\hline $\begin{array}{l}\text { Globulin }(\mathrm{g} / \mathrm{L}) \text {, } \\
\text { median (Q1, } \\
\text { Q3) }\end{array}$ & $23.0(21.0,25.2)$ & $23.1(22.2,25.2)$ & $22.1(20.4,27.8)$ & 0.525 \\
\hline $\begin{array}{l}\text { ALT (U/L), } \\
\text { median (Q1, } \\
\text { Q3) }\end{array}$ & $18.0(12.0,31.0)$ & $29.0(11.0,32.0)$ & $16.0(13.3,20.3)$ & 0.651 \\
\hline $\begin{array}{l}\operatorname{AST}(\mathrm{U} / \mathrm{L}), \\
\text { median (Q1, } \\
\text { Q3) }\end{array}$ & $24.0(18.0,26.0)$ & $24.0(15.0,24.0)$ & $24.0(19.5,28.3)$ & 0.608 \\
\hline $\begin{array}{l}\text { BUN } \\
(\text { mmol/L), } \\
\text { median (Q1, } \\
\text { Q3) }\end{array}$ & $3.1(2.5,3.4)$ & $3.0(2.4,3.4)$ & $3.1(2.5,3.4)$ & 0.608 \\
\hline $\begin{array}{l}\text { Creatinine } \\
(\text { umol/L), } \\
\text { median (Q1, } \\
\text { Q3) }\end{array}$ & $43.0(37.0,50.0)$ & $40.0(35.0,42.0)$ & $48.0(43.0,51.0)$ & 0.033 \\
\hline $\begin{array}{l}\text { LDH }(\mathrm{U} / \mathrm{L}) \text {, } \\
\text { median (Q1, } \\
\text { Q3) }\end{array}$ & $\begin{array}{l}202.0(171.0 \\
256.0)\end{array}$ & $\begin{array}{l}200.0(146.0 \\
231.0)\end{array}$ & $\begin{array}{l}212.0 \\
259.5)\end{array}$ & 0.307 \\
\hline $\begin{array}{l}\text { CK-MB (U/L), } \\
\text { median (Q1, } \\
\text { Q3) }\end{array}$ & $0.4(0.3,0.8)$ & $0.4(0.3,0.7)$ & $0.6(0.4,0.8)$ & 0.126 \\
\hline $\begin{array}{l}\text { Myoglobin } \\
\text { (g/L), median } \\
(\mathrm{Q} 1, \mathrm{Q} 3)\end{array}$ & $15.7(10.6,24.7)$ & $14.1(10.3,16.8)$ & $19.6(11.2,32.4)$ & 0.186 \\
\hline $\begin{array}{l}\mathrm{BNP}(\mathrm{pg} / \mathrm{mL}), \\
\text { median }(\mathrm{Q} 1, \\
\text { Q3) }\end{array}$ & $37.8(16.4,81.7)$ & $37.8(13.9,61.3)$ & $37.8(14.9,97.2)$ & 0.704 \\
\hline $\begin{array}{l}\text { D-Dimer } \\
(\mathrm{mg} / \mathrm{L}), \\
\text { median (Q1, } \\
\text { Q3) }\end{array}$ & $1.4(0.7,2.7)$ & $0.8(0.4,2.0)$ & $1.7(1.2,3.7)$ & 0.038 \\
\hline $\begin{array}{l}\text { Chest CT } \\
\text { findings }\end{array}$ & & & & \\
\hline $\begin{array}{l}\text { Ground-glass } \\
\text { opacity on the } \\
\text { left lung }\end{array}$ & $4(16.0 \%)$ & $2(18.2 \%)$ & $2(14.3 \%)$ & 1.000 \\
\hline $\begin{array}{l}\text { Ground-glass } \\
\text { opacity on the } \\
\text { right lung }\end{array}$ & $6(24.0 \%)$ & $2(18.2 \%)$ & $4(28.6 \%)$ & 0.895 \\
\hline $\begin{array}{l}\text { Bilateral } \\
\text { ground-glass } \\
\text { opacity }\end{array}$ & $5(20.0 \%)$ & $3(27.3 \%)$ & $2(14.3 \%)$ & 0.763 \\
\hline $\begin{array}{l}\text { Bilateral } \\
\text { patchy } \\
\text { shadowing }\end{array}$ & $10(40.0 \%)$ & $4(36.4 \%)$ & $6(42.9 \%)$ & 1.000 \\
\hline
\end{tabular}

Abbreviations: SD, standard deviation; ALT, Alanine transaminase; AST, Aspartate aminotransferase; BUN, Urea nitrogen; LDH, Lactate dehydrogenase; CK-MB, Creatine kinase isoenzyme-MB; BNP, B-type natriuretic peptid 
Table 3. Maternal characteristics and pregnancy outcomes in the first and second trimester

\begin{tabular}{llllllll}
\hline & P1 & P2 & P3 & P4 & P5 & P6 & P \\
Healthcare staff & No & Yes & Yes & No & No & No & N \\
Gestastional age at diagnosis $(w k s)$ & 5wk6d & $26 w k 3 d$ & $20 w k 3 d$ & $16 w k 3 d$ & $4 w k 4 d$ & $25 w k 3 d$ & 11 \\
Grading of disease & moderate & mild & moderate & mild & mild & severe & m \\
Pregnancy complications & None & None & None & None & None & Depression & N \\
Mechanical ventilation & No & No & No & No & No & No & N \\
ICU admission & No & No & No & No & No & No & N \\
Death & No & No & No & No & No & No & No \\
Termination of pregnancy and method & No & No & No & No & No & Induction of labor & In \\
Time to terminate pregnancy & No & No & No & No & No & $26 w k 5 d$ & G \\
GP & G1P0 & G3P1 & G2P0 & G2P1 & G2P1 & G1P1 & G \\
Intrauterine growth restriction & No & No & No & No & No & .. & .. \\
\hline
\end{tabular}

Abbreviations: GP, gestation parturition

Table 4. Maternal characteristics and pregnancy outcomes in the third trimester

\begin{tabular}{|c|c|c|c|c|c|c|c|c|c|c|c|c|}
\hline P 1 & P2 & P3 & $\mathrm{P} 4$ & P5 & P6 & P7 & P8 & P9 & P10 & P11 & P12 & P13 \\
\hline $\begin{array}{l}\text { Healthcâre } \\
\text { staff }\end{array}$ & Yes & No & No & No & No & No & Yes & No & No & No & No & No \\
\hline $\begin{array}{l}\text { Gestastianall } \\
\text { age } \\
\text { at } \\
\text { di- } \\
\text { ag- } \\
\text { no- } \\
\text { sis }\end{array}$ & $36 \mathrm{wk} 1 \mathrm{~d}$ & $39 w k 6 d$ & $38 \mathrm{wk} 5 \mathrm{~d}$ & $32 \mathrm{wk} 4 \mathrm{~d}$ & $39 w k 3 d$ & $37 \mathrm{wk} 5 \mathrm{~d}$ & $36 \mathrm{wk} 6 \mathrm{~d}$ & $34 \mathrm{wk} 3 \mathrm{~d}$ & $35 \mathrm{wk} 4 \mathrm{~d}$ & $34 \mathrm{wk} 1 \mathrm{~d}$ & $38 \mathrm{wk} 4 \mathrm{~d}$ & \\
\hline $\begin{array}{l}\text { Gradingmoderate } \\
\text { of } \\
\text { dis- } \\
\text { ease }\end{array}$ & emild & moderate & emild & mild & moderate & emoderate & emild & severe & moderate & emoderate & emild & \\
\hline $\begin{array}{l}\text { Pregnandypothy } \\
\text { com- } \\
\text { pli- } \\
\text { ca- } \\
\text { tions }\end{array}$ & ridintiem & None & None & None & None & GDM & None & None & None & None & None & \\
\hline $\begin{array}{c}\text { DeliveryCesarean } \\
\text { section }\end{array}$ & $\begin{array}{l}\text { nCesarear } \\
\text { section }\end{array}$ & $\begin{array}{l}\text { aCesarean } \\
\text { section }\end{array}$ & $\begin{array}{l}\text { aCesarean } \\
\text { section }\end{array}$ & $\begin{array}{l}\text { aCesarean } \\
\text { section }\end{array}$ & $\begin{array}{l}\text { aCesarean } \\
\text { section }\end{array}$ & $\begin{array}{l}\text { aCesarean } \\
\text { section }\end{array}$ & $\begin{array}{l}\text { ¿Cesarean } \\
\text { section }\end{array}$ & $\begin{array}{l}\text { aCesarean } \\
\text { section }\end{array}$ & $\begin{array}{l}\text { ¿Cesarean } \\
\text { section }\end{array}$ & $\begin{array}{l}\text { 1Cesarean } \\
\text { section }\end{array}$ & $\begin{array}{l}\text { Cesarear } \\
\text { section }\end{array}$ & \\
\hline $\begin{array}{l}\text { Gestatioß3alk6d } \\
\text { age } \\
\text { at } \\
\text { de- } \\
\text { liv- } \\
\text { ery }\end{array}$ & $37 w k 1 d$ & $40 \mathrm{wk} 5 \mathrm{~d}$ & $39 \mathrm{wk} 2 \mathrm{~d}$ & $39 \mathrm{wk} 3 \mathrm{~d}$ & $39 \mathrm{wk} 5 \mathrm{~d}$ & $39 \mathrm{wk} 3 \mathrm{~d}$ & $37 \mathrm{wk} 6 \mathrm{~d}$ & $36 \mathrm{wk} 1 \mathrm{~d}$ & $35 \mathrm{wk} 5 \mathrm{~d}$ & $37 \mathrm{wk} 5 \mathrm{~d}$ & $38 \mathrm{wk} 5 \mathrm{~d}$ & \\
\hline $\begin{array}{l}\text { Birthwe bold6 } \\
\text { (g) }\end{array}$ & 2890 & 3360 & 3450 & 2850 & 2650 & 3000 & 3400 & 2830 & 2300 & 3120 & 2650 & \\
\hline
\end{tabular}




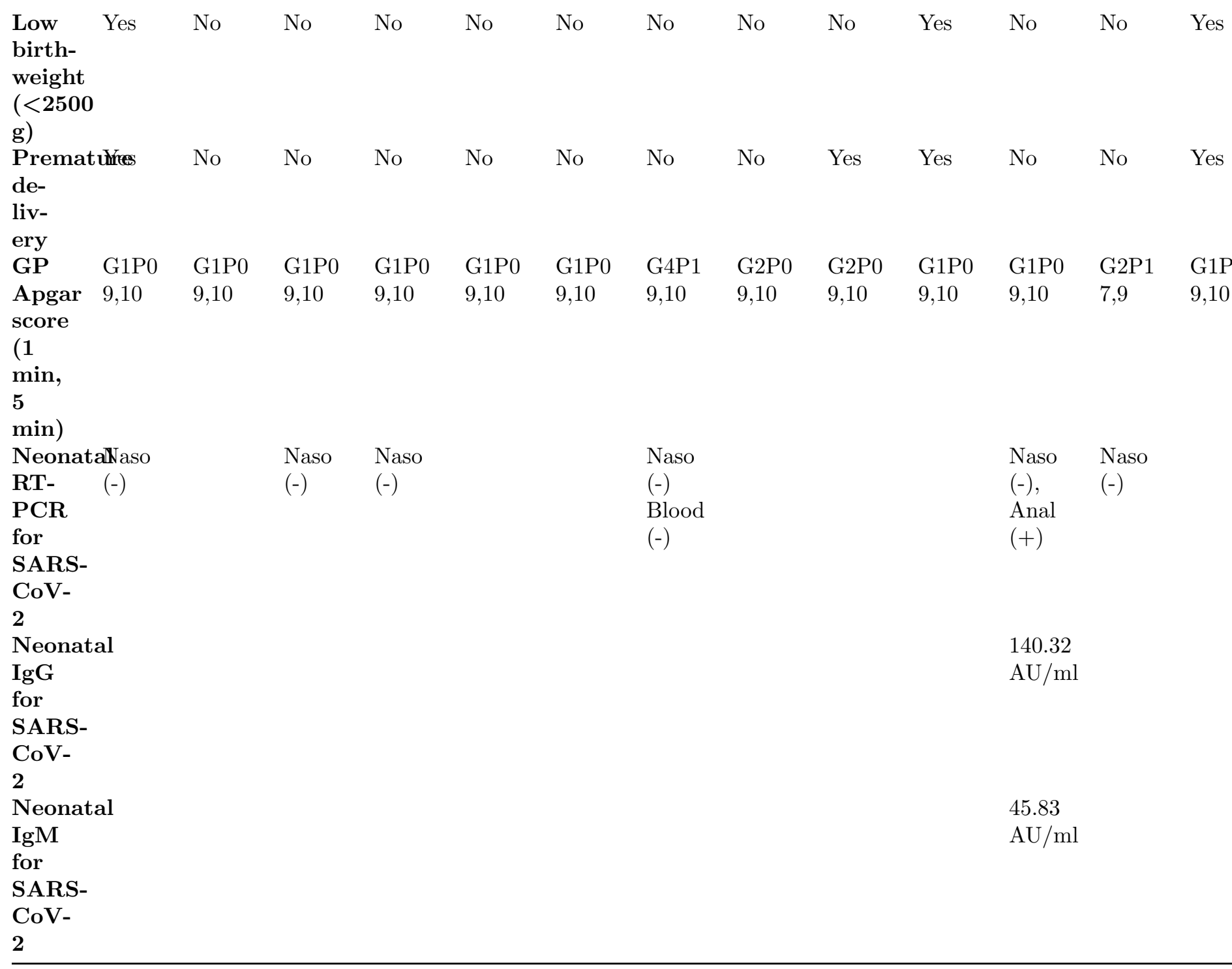

Abbreviations: GDM, gestational diabetes mellitus; PIH, pregnancy-induced hypertension; Naso, Nasopharyngeal swab; GP, gestation parturition; Anal, Anal swab

Hosted file

table1.doc available at https://authorea.com/users/344288/articles/470884-clinicalcharacteristics-and-perinatal-outcomes-of-women-with-covid-19-in-wuhan-retrospectivecase-series

Hosted file

table2.doc available at https://authorea.com/users/344288/articles/470884-clinicalcharacteristics-and-perinatal-outcomes-of-women-with-covid-19-in-wuhan-retrospectivecase-series

Hosted file 
table3.doc available at https://authorea.com/users/344288/articles/470884-clinicalcharacteristics-and-perinatal-outcomes-of-women-with-covid-19-in-wuhan-retrospectivecase-series

\section{Hosted file}

table4.doc available at https://authorea.com/users/344288/articles/470884-clinical-
characteristics-and-perinatal-outcomes-of-women-with-covid-19-in-wuhan-retrospective-
case-series 